\title{
SYNERGISTIC EFFECT OF GUM EXUDATE ON SUBSTITUTED PIPERIDINE-4-ONE IN CORROSION INHIBITION OF MILD STEEL IN ACIDIC MEDIUM
}

\author{
D. Jalajaa ${ }^{1, *}$, J. Mallika ${ }^{2}$ and S. Jyothi ${ }^{3}$ \\ ${ }^{1,3}$ Department of Chemistry, Kumaraguru College of Technology, \\ Coimbatore-641049,(Tamilnadu) India. \\ ${ }^{2}$ Departmentof Chemistry, PSG College of Arts and Science, \\ Coimbatore-641014, (Tamilnadu) India. \\ *E-mail: jalajaa.d.sci@kct.ac.in
}

\begin{abstract}
Moringa oleifera gum exudate a non-toxic organic compound, is introduced as a synergist to 3,5-Dimethyl-2,6diphenylpiperidin-4-one and the corrosion inhibition of mild steel in the Hydrochloric acid medium is studied using weight loss method, potentiodynamic polarization and electrochemical impedance spectroscopy. Results show that 3,5-Dimethyl-2,6-diphenylpiperidin-4-one alone provided an average inhibition of the corrosion of mild steel and it was found that the inhibition efficiency increased synergistically in the presence of Moringa oleifera gum exudate. The inhibition efficiency increased with increase in the concentration of the inhibitor but decreased with a rise in temperature. Polarization studies reveal that the inhibitor system is of a mixed type. Impedance studies point out that a protective film is formed on the mild steel surface in the presence of the inhibitor. Fourier transform infrared spectroscopy and scanning electron microscopy studies were used to investigate the nature of protective film formed on the mild steel surface.
\end{abstract}

Keywords: Corrosion inhibitor, Mild steel, Weight loss, Electrochemical impedance spectroscopy, FTIR, SEM, Surface morphology.

(C) RASĀYAN. All rights reserved

\section{INTRODUCTION}

Many metals and alloys used in different human activities are susceptible to different mechanisms of corrosion due to their exposure to different corrosive media. Among these, mild steel is very important. One of the methods used to reduce the rate of metallic corrosion is the addition of inhibitors ${ }^{1}$. Several inhibitors in use are also synthesized from cheap raw material or selected from compounds having heteroatoms in their aromatic or long-chain carbon system. Many researchers investigated the effect of substitution at 3-and 3,5-positions of 2,6-diphenylpiperidin-4-one on the corrosion inhibition of mild steel in acidic media ${ }^{2,4}$. However, most of these inhibitors are deleterious to the atmosphere. The high toxicity of the synthetic inhibitors helped the development of new kind of inhibitors, or new combinations of inhibitor which is harmless to the environment. Gums obtained from plants are solids consisting of mixtures of polysaccharides (carbohydrates) which are either water soluble or absorb water and swell up to form a gel or jelly when placed in water. They are insoluble in oils or organic solvents such as ether and alcohol. Some gums have also been found to be good corrosion inhibitors for the corrosion of metals in acidic solutions ${ }^{5,7}$. In the present study, the synergistic effect between Moringa oleifera (MO) gum exudate and 3,5-Dimethyl-2,6-diphenylpiperidin-4-one (DMDPP) on mild steel(MS) have been investigated using weight loss and electrochemical experiments.

\section{EXPERIMENTAL}

\section{Materials}

MS specimens of the following composition have been used for the present investigations Wt \%: $\mathrm{C}$ $0.07 \%$, P $0.008 \%$, Mn $0.34 \%$ rest Fe. DMDPP was prepared via reported procedures ${ }^{8,9}$. The MO gum 
was collected from the broken bark of the wounded trunk, washed with double distilled water to remove impurities like bark, dust, and sand etc. The estimated quantity of gum was put into $50 \mathrm{ml}$ of double distilled water, heated strongly and kept aside overnight, filtered through Whatman filter paper. Then it was kept in a desiccator for five days and from the glassy mass, the inhibitor was prepared by dissolving $1 \mathrm{~g}$ of dried and milled MO gum in $1000 \mathrm{ml}$ of water in a standard flask. The desired concentrations of the inhibitor were prepared by diluting the above stock solution with distilled water. The acid used for the study was also of AR grade and double distilled water was used for the dilution.

\section{Weight loss method}

The MS sheet was cut into rectangular pieces of dimension $2.5 \times 1 \times 0.1 \mathrm{~cm}$ and was abraded with a series of emery papers (grade180-220-400-500- 800-1000), washed with distilled water, degreased with acetone and dried. In this method previously weighed coupon was completely immersed in $100 \mathrm{ml} 1 \mathrm{M} \mathrm{HCl}$ with and without inhibitor. After a quantified interval of time, the specimens were removed, rinsed with water, dried in the warm air then stored in a desiccator and then reweighed to determine the weight loss. The inhibition efficiency (IE \%) and the corrosion rate (CR) was calculated using the following equations:

Corrosion rate $(\mathrm{mpy})=(87.6 \times \mathrm{W}) /(\rho \times \mathrm{A} \times \mathrm{T})$

Where, $\mathrm{W}=$ weight loss in $\mathrm{mg}, \rho=$ density in $\mathrm{mg}, \mathrm{A}=$ area of exposure in $\mathrm{cm}^{2}$ and $\mathrm{T}=$ time in hours.

Inhibition efficiency has been determined by using the following relationship:

I.E $(\%)=\mathrm{W}_{\mathrm{b}}-\mathrm{W}_{\mathrm{i}} / \mathrm{W}_{\mathrm{b}}$

Where, $\mathrm{W}_{\mathrm{b}}=$ Weight loss in uninhibited system and $\mathrm{W}_{\mathrm{i}}=$ the weight loss in the inhibited system.

\section{Electrochemical methods}

Electrochemical impedance spectroscopy (EIS) and potentiodynamic polarization techniques (PDP) were employed to observe the corrosion process for both inhibited and uninhibited media. The electrochemical cell was composed of the platinum electrode as a counter electrode, saturated calomel electrode acts as a counter electrode and MS specimen acts as a working electrode. The electrochemical impedance measurements were carried out over the frequency range of $10 \mathrm{KHz}$ to $0.01 \mathrm{~Hz}$ carried with an amplitude of the $10 \mathrm{mV}$. The electrochemical parameters such as double layer capacitance $\left(\mathrm{C}_{\mathrm{dl}}\right)$ and charge transfer resistance $\left(R_{\mathrm{ct}}\right)$ were calculated from impedance measurements. The potentiodynamic polarization measurements were made for a potential range of $-200 \mathrm{mV}$ to $+200 \mathrm{mV}$ with respect to open circuit potential, at a scan rate of $1 \mathrm{mV} / \mathrm{sec}$. The parameters such as the corrosion potential ( $\mathrm{E}_{\mathrm{corr}}$ ), corrosion current ( $\left.I_{\text {corr }}\right)$ were obtained. Tafel slopes $b_{a}$ and $b_{c}$ were obtained in the absence and in the presence of inhibitors.

\section{FTIR}

SHIMADZU model- IR AFFINITY-1were used to record the FTIR for DMDPP and MO system and the scrapped product.

\section{SEM Analysis}

SEM images of plain polished MS surface before immersion in $\mathrm{HCl}$, uninhibited and inhibited mild steel specimens without and with DMDPP and MO system were recorded to study the nature of protective film formed on the MS surface.

\section{Weight Loss Measurement}

\section{RESULTS AND DISCUSSION}

The corrosion inhibition of mild steel in $1 \mathrm{M}$ Hydrochloric acid in the absence and presence of MO gum and DMDPP are studied using weight loss technique. Experiments were carried at room temperature and elevated temperatures for one hour and higher immersion periods. The inhibition efficiencies and corrosion rates for the MO gum and DMDPP at different concentrations are calculated and the results are 
RASĀYAN $J$. Chem.

Vol. 10 | No. 4 |1271-1279 | October - December | 2017

given in Table-1.

Table-1: Inhibition efficiencies and Corrosion rates of various concentrations of MO Gum exudate and DMDPP on $\mathrm{MS}$ in $1 \mathrm{M} \mathrm{HCl}$ for one-hour immersion at room temperature.

\begin{tabular}{c|c|c|c|c|c|c}
\hline S. No. & $\begin{array}{c}\text { Conc. } \\
\text { MO } \\
(\mathrm{g} / \mathrm{L})\end{array}$ & $\begin{array}{c}\mathrm{CR} \\
(\mathrm{mpy})\end{array}$ & $\begin{array}{c}\mathrm{IE} \\
(\%)\end{array}$ & $\begin{array}{c}\text { Conc. } \\
\text { DMDPP } \\
(\mathrm{mM})\end{array}$ & $\begin{array}{c}\mathrm{CR} \\
(\mathrm{mpy})\end{array}$ & $\begin{array}{c}\mathrm{IE} \\
(\%)\end{array}$ \\
\hline 1 & Blank & 0.0455 & - & Blank & 0.04133 & - \\
\hline 2 & 2 & 0.0166 & 63.33 & 2 & 0.02009 & 51.37 \\
\hline 3 & 4 & 0.0159 & 64.89 & 4 & 0.01934 & 53.21 \\
\hline 4 & 6 & 0.0125 & 72.50 & 6 & 0.01820 & 55.96 \\
\hline 5 & 8 & 0.0119 & 73.75 & 8 & 0.01782 & 56.88 \\
\hline 6 & 10 & 0.0090 & 80.08 & 10 & 0.01858 & 55.04 \\
\hline
\end{tabular}

From the Table-1 it is evident that the corrosion rate tends to decrease in the presence of MO gum as compared to blank acid. The percentage inhibition efficiency increases up to $10 \mathrm{~g} / \mathrm{L}$ of $\mathrm{MO}$ and a further increase in concentration does not significantly influence percentage inhibition efficiency. However, the results of DMDPP show the direct relationship between the concentration of the inhibitor and its percentage inhibition efficiency. The corrosion rates are reduced in the presence of DMDPP up to $8 \mathrm{mM}$ as compared to blank solution and beyond that the corrosion rate increases. This behavior is due to the fact that the adsorption coverage of inhibitors on MS surface increases with the inhibitor concentration ${ }^{10}$. The inhibition efficiency of DMDPP in the absence and presence of MO gum are analyzed at higher immersion periods and the results are tabulated in Table-2.

Table-2: Inhibition efficiencies of optimum concentrations of MO gum and DMDPP in $1 \mathrm{M} \mathrm{HCl} \mathrm{for} \mathrm{various}$ immersion periods

\begin{tabular}{|c|c|c|c|c|c|c|c|c|}
\hline \multirow[t]{2}{*}{ S. No. } & \multicolumn{4}{|c|}{ Without MO gum } & \multicolumn{4}{|c|}{ With MO gum } \\
\hline & $\begin{array}{l}\text { Time of } \\
\text { immersion } \\
\text { (h) }\end{array}$ & $\begin{array}{c}\text { Test } \\
\text { solution }\end{array}$ & $\begin{array}{l}\text { CR } \\
\text { (mpy) }\end{array}$ & $\begin{array}{l}\mathrm{IE} \\
(\%)\end{array}$ & $\begin{array}{l}\text { Time of } \\
\text { immersion } \\
\text { (h) }\end{array}$ & $\begin{array}{c}\text { Test } \\
\text { solution }\end{array}$ & $\begin{array}{c}\text { CR } \\
\text { (mpy) }\end{array}$ & $\begin{array}{l}\mathrm{IE} \\
(\%)\end{array}$ \\
\hline \multirow[b]{2}{*}{1} & \multirow[b]{2}{*}{2} & Blank & 0.07243 & - & \multirow[b]{2}{*}{2} & Blank & 0.07243 & - \\
\hline & & $\begin{array}{c}8 \mathrm{ml} \\
\text { DMDPP }\end{array}$ & 0.02957 & 59.16 & & $\begin{array}{c}8 \mathrm{ml} \\
\mathrm{DMDPP} \\
+10 \mathrm{ml} \mathrm{MO} \\
\end{array}$ & 0.01981 & 72.64 \\
\hline \multirow[b]{2}{*}{2} & \multirow[b]{2}{*}{4} & Blank & 0.06238 & - & \multirow[b]{2}{*}{4} & Blank & 0.06238 & - \\
\hline & & $\begin{array}{c}8 \mathrm{ml} \\
\text { DMDPP }\end{array}$ & 0.02483 & 60.18 & & $\begin{array}{c}8 \mathrm{ml} \\
\text { DMDPP } \\
+10 \mathrm{ml} \mathrm{MO} \\
\end{array}$ & 0.01485 & 76.18 \\
\hline \multirow[b]{2}{*}{3} & \multirow[b]{2}{*}{6} & Blank & 0.08646 & & \multirow[b]{2}{*}{6} & Blank & 0.08646 & - \\
\hline & & $\begin{array}{c}8 \mathrm{ml} \\
\text { DMDPP }\end{array}$ & 0.03419 & 60.45 & & $\begin{array}{c}8 \mathrm{ml} \\
\text { DMDPP } \\
+10 \mathrm{ml} \mathrm{MO} \\
\end{array}$ & 0.01283 & 85.76 \\
\hline \multirow[b]{2}{*}{4} & \multirow[b]{2}{*}{8} & Blank & 0.08011 & - & \multirow[b]{2}{*}{8} & Blank & 0.08011 & - \\
\hline & & $\begin{array}{c}8 \mathrm{ml} \\
\text { DMDPP }\end{array}$ & 0.02962 & 63.01 & & $\begin{array}{c}8 \mathrm{ml} \\
\mathrm{DMDPP} \\
+10 \mathrm{ml} \mathrm{MO}\end{array}$ & 0.00995 & 88.36 \\
\hline 5 & 12 & Blank & 0.05751 & - & 12 & Blank & 0.05751 & - \\
\hline
\end{tabular}


RASĀYAN $J$. Chem.

Vol. 10 | No. 4 |1271-1279 | October - December | 2017

\begin{tabular}{|c|c|c|c|c|c|c|c|c|}
\hline & & $\begin{array}{c}8 \mathrm{ml} \\
\text { DMDPP }\end{array}$ & 0.01994 & 65.33 & & $\begin{array}{c}8 \mathrm{ml}+ \\
\mathrm{DMDPP} \\
10 \mathrm{ml} \mathrm{MO} \\
\end{array}$ & 0.00679 & 88.62 \\
\hline \multirow[b]{2}{*}{6} & \multirow[b]{2}{*}{24} & Blank & 0.07774 & - & \multirow[b]{2}{*}{24} & Blank & 0.07774 & - \\
\hline & & $\begin{array}{c}8 \mathrm{ml} \\
\text { DMDPP }\end{array}$ & 0.03530 & 54.59 & & $\begin{array}{c}8 \mathrm{ml} \\
\text { DMDPP } \\
+10 \mathrm{ml} \mathrm{MO} \\
\end{array}$ & 0.00974 & 87.45 \\
\hline
\end{tabular}

The percentage inhibition efficiency is observed to be higher in the inhibiting solutions containing MODMDPP combination than that of the DMDPP alone. Examination of the table further reveals that the corrosion rate of MS in solutions of DMDPP-MO gum combination is lower than that of the test solution without MO gum. The inhibition efficiency was found to be synergistically enhanced in the presence of MO gum and increased with the increase in immersion time from 1-12 hours. Analysis of the results in Table 2 shows that the MO gum and DMDPP in ratio 10:8 give better results. A combination of $10 \mathrm{~g} / \mathrm{L}$ MO gum and $8 \mathrm{mM}$ DMDPP reduces the corrosion rate drastically and the percentage inhibition efficiency gets increased from 13\% - $25 \%$ when compared to DMDPP alone. The corrosion behavior of MS in $1 \mathrm{M} \mathrm{HCl}$ in the presence and absence of $\mathrm{MO}$ gum in combination with DMDPP of optimum concentration is studied in the temperature range of 303- $343 \mathrm{~K}$. The corresponding data are given in Table-3.

Table-3: Inhibition efficiencies of optimum concentrations of MO gum and DMDPP in $1 \mathrm{M} \mathrm{HCl}$ at various temperatures

\begin{tabular}{|c|c|c|c|c|c|c|c|c|}
\hline \multirow[b]{2}{*}{ S. No. } & \multicolumn{4}{|c|}{ Without MO gum } & \multicolumn{4}{|c|}{ With MO gum } \\
\hline & $\begin{array}{l}\text { Temperature } \\
(\mathrm{K})\end{array}$ & $\begin{array}{c}\text { Test } \\
\text { solution }\end{array}$ & $\begin{array}{c}\text { CR } \\
\text { (mpy) }\end{array}$ & $\begin{array}{l}\mathrm{IE} \\
(\%)\end{array}$ & $\begin{array}{l}\text { Temperature } \\
(\mathrm{K})\end{array}$ & $\begin{array}{c}\text { Test } \\
\text { solution }\end{array}$ & $\begin{array}{c}\text { CR } \\
\text { (mpy) }\end{array}$ & $\begin{array}{l}\mathrm{IE} \\
(\%)\end{array}$ \\
\hline \multirow[b]{2}{*}{1} & \multirow[b]{2}{*}{303} & Blank & 0.14903 & - & \multirow[b]{2}{*}{303} & Blank & 0.14903 & - \\
\hline & & $\begin{array}{c}8 \mathrm{ml} \\
\text { DMDPP }\end{array}$ & 0.05233 & 64.89 & & $\begin{array}{c}8 \mathrm{ml} \\
\text { DMDPP } \\
+10 \mathrm{ml} \mathrm{MO}\end{array}$ & 0.02839 & 83.97 \\
\hline \multirow[b]{2}{*}{2} & \multirow[b]{2}{*}{313} & Blank & 0.17899 & - & \multirow[b]{2}{*}{313} & Blank & 0.17899 & - \\
\hline & & $\begin{array}{c}8 \mathrm{ml} \\
\text { DMDPP }\end{array}$ & 0.07584 & 57.63 & & $\begin{array}{c}8 \mathrm{ml} \\
\text { DMDPP } \\
+10 \mathrm{ml} \mathrm{MO} \\
\end{array}$ & 0.04171 & 76.69 \\
\hline \multirow[b]{2}{*}{3} & \multirow[b]{2}{*}{323} & Blank & 0.24383 & - & \multirow[b]{2}{*}{323} & Blank & 0.24383 & - \\
\hline & & $\begin{array}{c}8 \mathrm{ml} \\
\text { DMDPP }\end{array}$ & 0.12855 & 47.28 & & $\begin{array}{c}8 \mathrm{ml} \\
\text { DMDPP } \\
+10 \mathrm{ml} \mathrm{MO} \\
\end{array}$ & 0.07394 & 69.67 \\
\hline \multirow[b]{2}{*}{4} & \multirow[b]{2}{*}{333} & Blank & 0.30660 & - & \multirow[b]{2}{*}{333} & Blank & 0.30660 & - \\
\hline & & $\begin{array}{c}8 \mathrm{ml} \\
\text { DMDPP }\end{array}$ & 0.21810 & 28.88 & & $\begin{array}{c}8 \mathrm{ml} \\
\text { DMDPP } \\
+10 \mathrm{ml} \mathrm{MO}\end{array}$ & 0.14714 & 52.00 \\
\hline \multirow[b]{2}{*}{5} & \multirow[b]{2}{*}{343} & Blank & 0.4072 & - & \multirow[b]{2}{*}{343} & Blank & 0.4072 & - \\
\hline & & $\begin{array}{c}8 \mathrm{ml} \\
\text { DMDPP }\end{array}$ & 0.12850 & 15.31 & & $\begin{array}{c}8 \mathrm{ml} \\
\mathrm{DMDPP} \\
+10 \mathrm{ml} \mathrm{MO}\end{array}$ & 0.07394 & 38.93 \\
\hline
\end{tabular}

In the temperature range studied, the corrosion rate was found to increase with an increase in the temperature for both inhibited and uninhibited acid solutions. From the table it is clear that the percentage inhibition efficiency increases with MO gum in combination with DMDPP at all temperatures than 
DMDPP alone. MO gum act as a primary synergist which enhances the percentage inhibition efficiency of DMDPP at all temperatures. It is also evident from the table that by increasing the temperature from 303$343 \mathrm{~K}$ the $\%$ IE decreases from 83.97 - $38.93 \%$ with MO gum. The decrease in percentage inhibition efficiency with increase in temperature from 303-343 K may be probably due to an increased rate of desorption of MO-DMDPP from the mild steel surface ${ }^{11,12}$. Temperature studies help in the calculation of thermodynamic parameters like the free energy of adsorption $\left(\Delta \mathrm{G}_{\mathrm{ads}}\right)$, enthalpy of adsorption $\left(\Delta \mathrm{H}_{\mathrm{ads}}\right)$ and entropy of adsorption $\left(\Delta \mathrm{S}_{\mathrm{ads}}\right)$. The negative values of $\Delta \mathrm{G}_{\mathrm{ads}}$ suggest that the adsorption of MODMDPP on the MS surface is spontaneous. However, the values of $\Delta \mathrm{G}_{\text {ads }}$ with MO gum in a combination of DMDPP around or less than $-20 \mathrm{~kJ} \mathrm{~mol}^{-1}$ are associated with the electrostatic interaction between charged molecules and the charged metal surface (physisorption) ${ }^{10}$. The negative values of $\Delta \mathrm{H}_{\text {ads }}$ reflect the exothermic behavior of the adsorption of MO- DMDPP on the MS surface. The positive values of $\Delta \mathrm{S}_{\text {ads }}$ suggest that the adsorption process is accompanied by an increase in entropy, which is the driving force for the adsorption of MO- DMDPP on them MS surface ${ }^{13}$.In order to clarify the nature of adsorption, theoretical fitting of the surface coverage values to different isotherms was undertaken and the value of correlation coefficient was used to determine the best-fit isotherm. Langmuir adsorption isotherm was found to be the best fit.

\section{Electrochemical Methods}

Electrochemical experiments such as potentiodynamic polarization and electrochemical impedance spectroscopy measurements were performed in order to analyze the synergistic influence of MO gum on DMDPP on corrosion of MS in $1 \mathrm{M} \mathrm{HCl}$.

A $-0.1000$

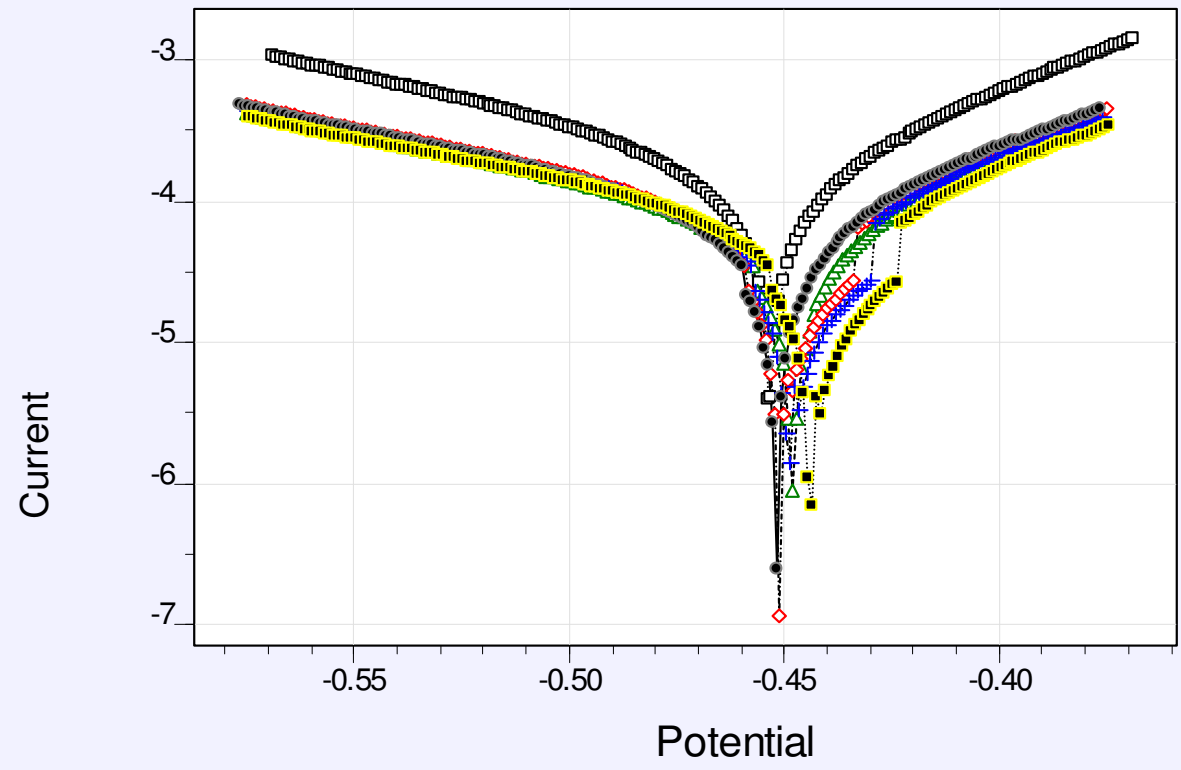

Fig.-1: Tafel plots of inhibited and uninhibited system with MO-DMDPP

Fig.-1 presents the Tafel polarization characteristics of MS in $1 \mathrm{M} \mathrm{HCl}$ for inhibited and uninhibited system. The inhibited system of polarization curves consists of both in the absence and presence of MO gum in DMDPP. It can be seen from the plot that there is no significant change in the corrosion potential ( $\left.\mathrm{E}_{\text {corr }}\right)$ suggesting the inhibitor system is a mixed type. It is also evident that the corrosion current densities $\left(\mathrm{I}_{\mathrm{corr}}\right)$ of the inhibited system are significantly reduced compared to the uninhibited system. From the figure it is also clear that the $\mathrm{I}_{\text {corr }}$ value of DMDPP is much higher than that of MO- DMDPP and the corresponding inhibition efficiency of MO-DMDPP is greater suggesting that the adsorption of the 
inhibitor molecules on metal surface makes a physical barrier for the mass and charge transfer, providing high degree of protection to the metal surface ${ }^{14}$. MO gum greatly enhances the percentage inhibition efficiency of DMDPP due to the synergistic effect of MO on DMDPP.Electrochemical impedance spectroscopy was used to obtain information about the kinetics and mechanism of the mild steel corrosion inhibition of MO- DMDPP system.

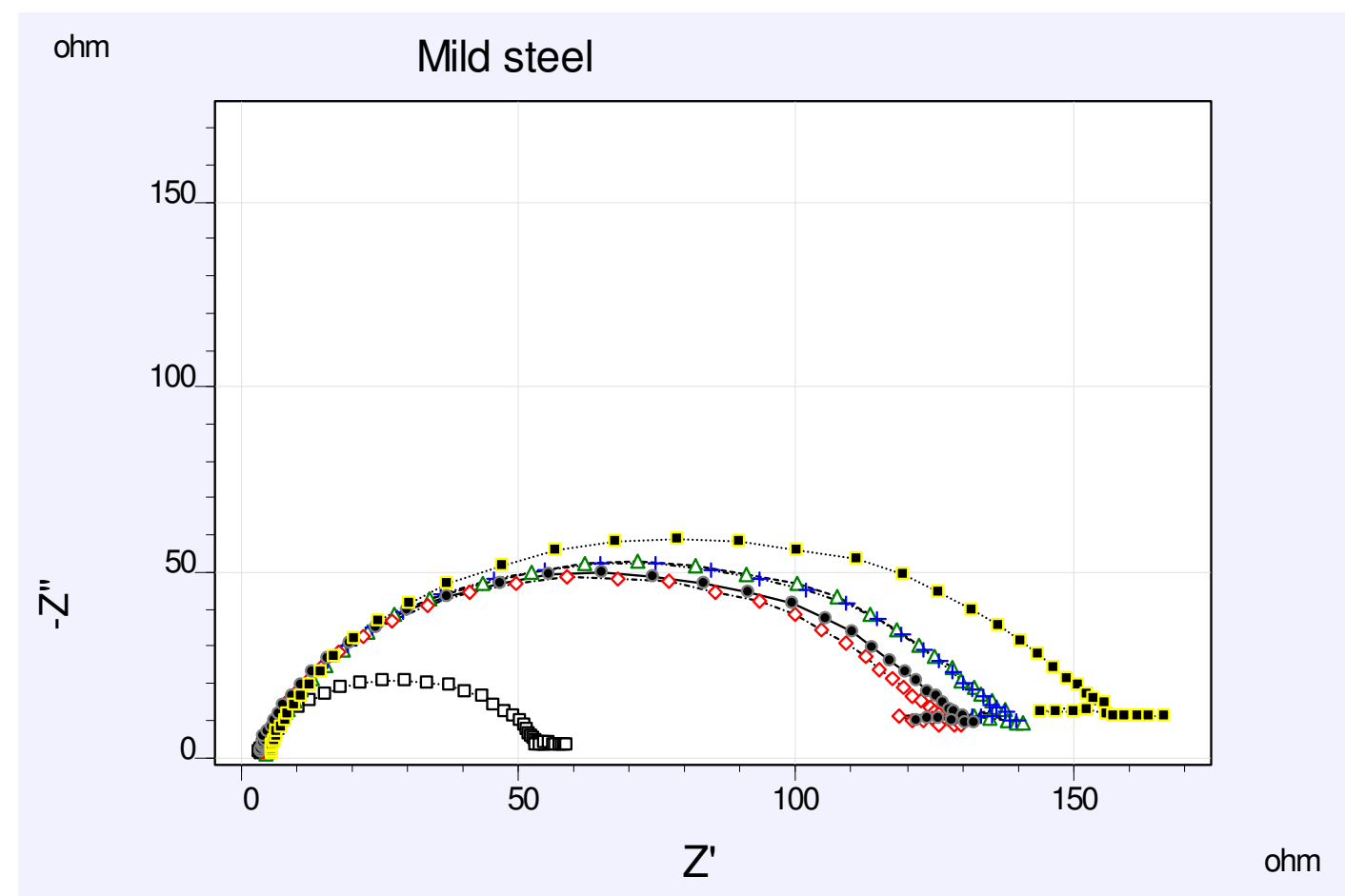

Fig.-2: Nyquist plots of inhibited and uninhibited system with MO-DMDPP

Figure-2 shows the impedance response of mild steel in $1 \mathrm{M} \mathrm{HCl}$ with and without inhibitor represented via Nyquist plots. The diameter of Nyquist plots increased upon the addition of inhibitor which resulted in strengthening the inhibitive film. The double layer capacitance $(\mathrm{Cdl})$ decreases and the charge transfer resistance (Rct) increases in the presence of inhibitor. It can be attributed to a decrease in the local dielectric constant and an increase in the thickness of the electrical double layer. This again suggests that the inhibitor molecules function by adsorption at the mild steel-solution interface ${ }^{15}$. The percentage inhibition efficiency calculated using Rct values clearly reflects the synergistic effect of MO gum on DMDPP. The Rct values of the plot without MO gum are lower when comparing to plot with MO gum. The corresponding percentage inhibition efficiency values show that MO gum greatly influences the corrosion inhibition of DMDPP. These results are in agreement with both weight loss and potentiodynamic polarisation methods.

\section{FTIR}

FTIR spectroscopic studies revealed that the phytochemical constituents of the gum and the functional group in DMDPP were adsorbed on the surface resulting in the characteristic adsorption bands of the functional group in MO- DMDPP. The FTIR spectra of the crude MO and that of the products on the surface of MS after immersion in $1 \mathrm{M} \mathrm{HCl}$ containing $10 \mathrm{~g} / \mathrm{L}$ of $\mathrm{MO}$ and $8 \mathrm{mM}$ of DMDPP for 12 hours [Figs.-3a and 3b] provided information concerning the strength of the bonds between the metal surface and the inhibitor molecules. Comparison of the above figures clearly indicates that the characteristic frequencies corresponding to the various functional groups are shifted indicating the adsorption of the inhibitor molecule on the MS surface. 
RASĀYAN J. Chem.

Vol. 10 | No. 4 |1271-1279 | October - December | 2017
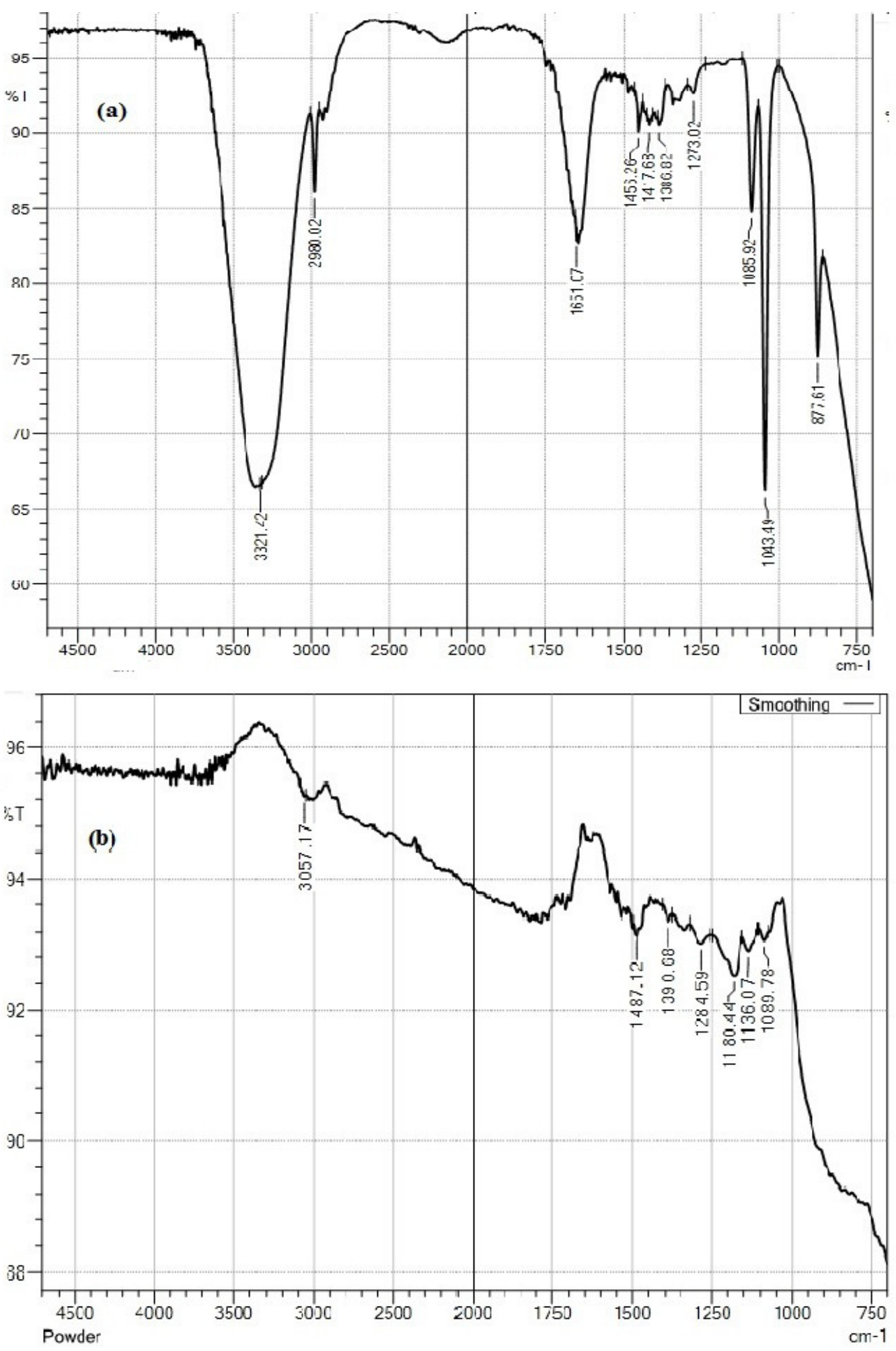

SEM Analysis

Fig.-3: FTIR spectra of (a) MO gum- DMDPP and (b)Scrapped Product

Figure-4a shows a SEM micrograph of polished mild steel specimen, Fig.-4b shows for mild steel immersed in $1 \mathrm{M} \mathrm{HCl}$ for $6 \mathrm{hrs}$ in the absence of MO-DMDPP system and Fig.-4c in presence of MODMDPP system for 6 hrs. The morphology in Fig.-4a shows a smooth surface, in Fig.-4b a rough surface 
RASĀYAN J. Chem.

Vol. 10 | No. 4 |1271-1279 | October - December | 2017

characteristic of the uniform corrosion of mild steel in acid, in Fig $4 \mathrm{c}$ a coated surface indicating that the surface is covered by MO-DMDPP system.
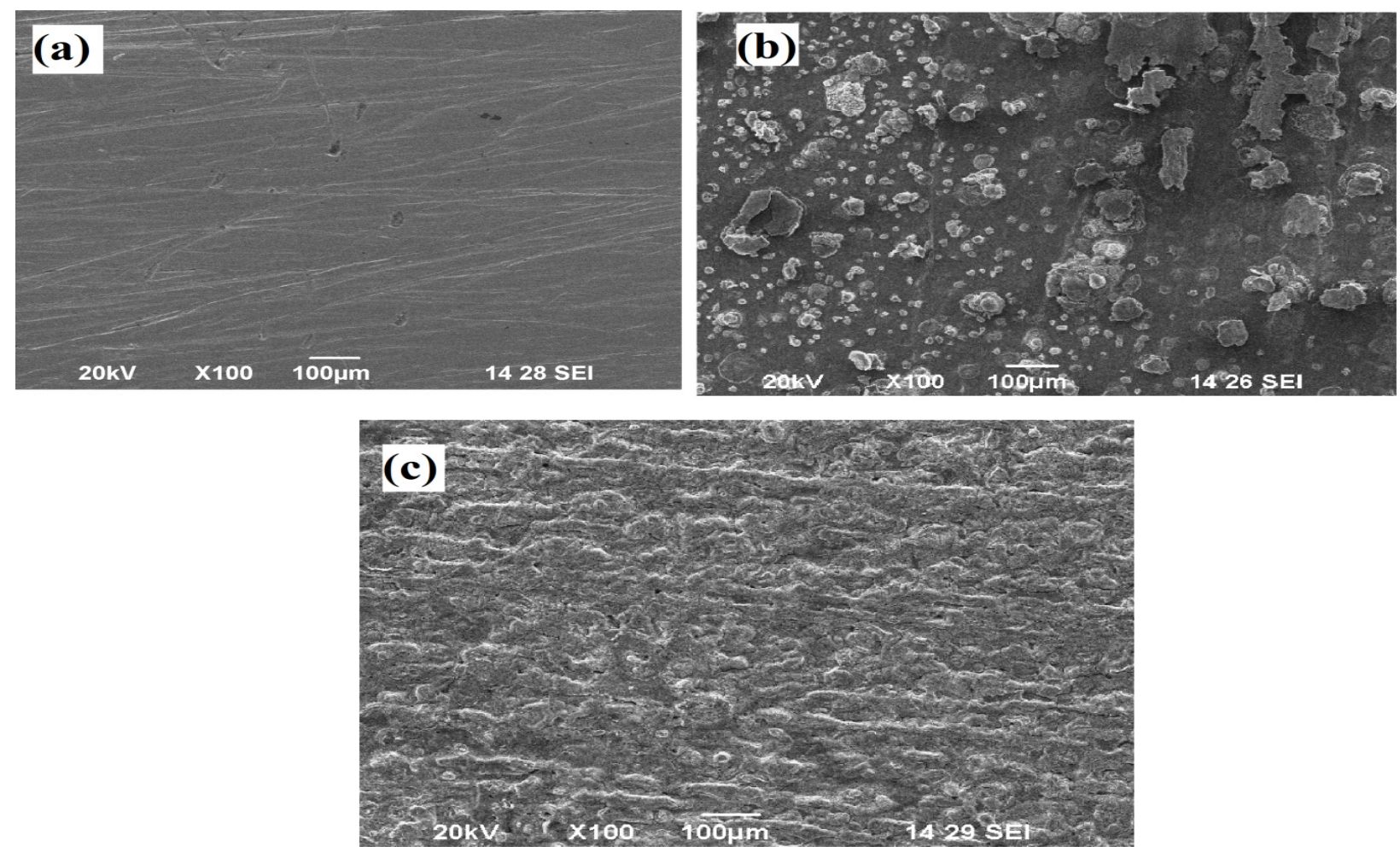

Fig.-4: Sem photograph of (a) polished mild steel surface before immersion, (b) Sem photograph of mild steel plate immersed in $1 \mathrm{M} \mathrm{HCl}$ for $6 \mathrm{hrs}$ in the absence of MO-DMDPP, (c)Sem photograph of mild steel plate immersed in $1 \mathrm{M} \mathrm{HCl}$ for $6 \mathrm{hrs}$ in the presence of MO-DMDPP

\section{CONCLUSION}

Based on the results obtained from weight loss methods and electrochemical measurements, the following conclusions are drawn:

- Results showed that DMDPP alone provides an average inhibition of the corrosion of MS and it was also found that the percentage inhibition efficiency increased synergistically in the presence of MO gum exudate.

- The inhibition efficiency increased with increase in the concentration of the inhibitor but decreased with a rise in temperature.

- Polarization studies revealed that the MO-DMDPP is of a mixed type.

- Impedance studies point out that a protective film is formed on the MS surface in the presence of the inhibitor.

- FTIR and SEM were used to investigate the nature of protective film formed on the mild steel surface.

\section{REFERENCES}

1. Aprael S. Yaro, A. Anees, A. Khadom, and Rafal K. Wael, Alexandria Engineering Journal, 52,129(2013).

2. T. Brindha, J. Mallika, and V. Sathyanarayana Moorthy, J. Mater. Environ. Sci., 6 (1), 191 (2015).

3. A. N. Senthilkumar, K. Tharini and M. G. Sethuraman, Surface Review and Letters,16(1), 141(2009).

4. Glory Tharial Xavier, Brindha Thirumalairaj and Mallika Jaganathan, International Journal of Corrosion, Article ID 410120, (2015) 
RASĀYAN $J$. Chem.

Vol. 10 | No. 4 |1271-1279 | October - December | 2017

5. S. K. Sharma and A. Sharma, Green Corrosion Chemistry and Engineering, Wiley-VCH Publications, Weinheim, 157(2011).

6. S. A. Umoren, Portugaliae Electrochimica Acta ,27(5),565 (2009).

7. M. Abdallah, Portugaliae Electrochimica Acta ,22,161 (2004).

8. M. B. Balasubramanian and N. Padma, Tetrahedron, 19(12), 2135(1963).

9. C. R. Noller and V. Baliah, Journal of the American Chemical Society, 70(11), 3853(1948).

10. Xianghong Li, Shuduan Deng and Hui Fu, Corrosion Science, 62, 163 (2012).

11. Xianghong Li, Shuduan Deng and Hui Fu, Progress in Organic Coating, 67,420(2010).

12. I.B. Ibot and N. O. Obi- Egbedi, Current Applied Physics, 11, 382 (2011).

13. B.G. Ateya, B.E. El-Anadouli, F.M. El-Nizamv, Corrosion Science, 24,509(1984).

14. Husnu Gerengi, Katarzyna Schaefer and H. Ibrahim Sahin, Journal of Industrial and Engineering Chemistry, 18, 2204(2012).

15. W.J. Lorenz and F. Mansfeld, Corrosion Science, 21, 647(1981).

[RJC-1926/2017] 